\title{
Survey of Fusarium spp. Causing Wheat Crown Rot in Major Winter Wheat Growing Regions of China
}

Xiang-xiang Zhang, Institute of Plant Protection, Jiangsu Academy of Agricultural Sciences, Nanjing 210014, China; and College of Life Sciences, Nanjing Agricultural University, Nanjing, 210095, China; Hai-yan Sun, Cheng-mei Shen, and Wei Li, Institute of Plant Protection, Jiangsu Academy of Agricultural Sciences, Nanjing 210014, China; Han-shou Yu, College of Life Sciences, Nanjing Agricultural University, Nanjing, 210095, China; and Huai-gu Chen, Institute of Plant Protection, Jiangsu Academy of Agricultural Sciences, Nanjing 210014, China

\begin{abstract}
Zhang, X.-X., Sun, H.-Y., Shen, C.-M., Li, W., Yu, H.-S., and Chen, H.-G. 2015. Survey of Fusarium spp. causing wheat crown rot in major winter wheat growing regions of China. Plant Dis. 99:1610-1615.

Fusarium crown rot of wheat has become more prevalent in China. To investigate the phylogenetic structure of Fusarium causing wheat crown rot in China, wheat basal stems with symptoms of the disease were collected from 2009 to 2013 in Jiangsu, Anhui, Henan, Hebei, and Shandong provinces. In total, 175 Fusarium isolates were collected and their mycotoxin chemotypes and distribution were identified. Among the 175 isolates, 123 were Fusarium asiaticum; 95 of these were the chemotype 3-acetyl-deoxynivalenol (3-AcDON) and 28 were nivalenol (NIV). Thirty-seven isolates belonged to $F$. graminearum, which were all $15-\mathrm{AcDON}$. Smaller numbers of isolates consisted of

$F$. acuminatum, $F$. pseudograminearum, and $F$. avenaceum. The virulence of $F$. asiaticum and $F$. graminearum isolates on wheat crowns and heads was comparable. The virulence of isolates of the DON and NIV chemotype were statistically similar, but DON tended to be more aggressive. The DON concentrations in grains from wheat heads inoculated with isolates causing either Fusarium head blight or crown rot were similar. In the five provinces, $F$. asiaticum of the 3-AcDON chemotype was the predominant pathogen causing crown rot, followed by $F$. graminearum. Recent changes in causal Fusarium species, chemotypes, and distribution in China are discussed.
\end{abstract}

Species of the fungal ascomycete Fusarium cause a necrosis and dry rot of the wheat crown, basal stem, and root tissue known as crown rot, which reduces grain yield (6). Although crown rot of wheat was formerly considered restricted to certain geographic areas such as Australia (5), recent reports have shown that it occurs in most cereal-producing regions of the world (30) and is of economic concern in Australia (5), Europe (22), North America (30), South America (5), West Asia, North Africa (3,19), and South Africa (11). It is particularly damaging in Queensland, northern New South Wales, and parts of South Australia (37).

In some regions, the predominant pathogens causing crown rot of wheat are members of the Fusarium graminearum species complex (FGSC). Based on genealogical concordance phylogenetic species recognition (GCPSR) and multilocus genotyping (MLGT) of strains, the FGSC comprises 16 or more phylogenetically distinct species or lineages characterized morphologically as $F$. graminearum Petch (teleomorph: Gibberella zeae [Schweinitz] Petch) (26). Most species within the FGSC appear to be restricted to specific geographic regions. In the United States, Europe, and Canada, the principal causes of crown rot are $F$. pseudograminearum, $F$. culmorum, and $F$. graminearum $(16,23,29)$. In Australia, $F$. pseudograminearum is the predominant pathogen, according to surveys of the eastern wheat belt conducted during the 1970s (4). In Asia, Bipolaris sorokiniana and F. graminearum predominate (10). In China, B. sorokiniana, F. graminearum, and $F$. asiaticum have been found in major wheat-growing regions $(7,13)$.

Infection by Fusarium species reduces crop yield in the field and in storage. In addition to yield reduction, infection is often associated with the accumulation of the mycotoxin deoxynivalenol (DON) in grain (18), which poses considerable health risk to animals and people (8). DON belongs to the type B trichothecene family of

Corresponding authors: H.-S. Yu and H.-G. Chen, E-mails: yuhans@njau. edu.cn and huaigu@jaas.ac.cn

Accepted for publication 2 December 2014.

http://dx.doi.org/10.1094/PDIS-04-14-0422-RE

(C) 2015 The American Phytopathological Society secondary metabolites (8). Based on chemical structure, including the acetylation position, three $\mathrm{B}$ trichothecene chemotypes have been identified within the FGSC, namely nivalenol and its acetylated derivative 4-acetylnivalenol (NIV), 3-acetyldeoxynivalenol (3-AcDON), and 15 -acetyldeoxynivalenol $(15-\mathrm{AcDON})(15,36)$. The different toxicological effects of NIV, 3-AcDON, and 15-AcDON make their identification in specific geographic regions important. Both DON and NIV chemotypes of crown rot pathogens have been reported in China (13). However, their exact distribution in the major winter wheat producing areas of China is unknown.

Some reports showed that trichothecenes are virulence factors in plants, which may contribute to colonization of the wheat crown by the pathogen (18). However, Von der Ohe et al. (34) reported that there was no significant difference in virulence between 3 -AcDON and $15-A c D O N$ strains in wheat heads infected by Fusarium head blight (FHB). Shen et al. (29) also reported that 3-AcDON and 15AcDON isolates had similar levels of virulence, although the DON isolates were significantly more virulent than NIV isolates. Yet there has been no study regarding the differences in virulence in wheat crowns of 3-AcDON and 15-AcDON strains of the pathogens that cause crown rot of wheat.

In recent years, wheat crown rot has become more serious in parts of China and poses a serious threat to wheat production. For the present study we collected the bases of diseased wheat stems to identify and determine the distribution of chemotypes of crown rot pathogens in major winter wheat growing regions of China. We then investigated how the chemotypes, their phylogenetic species, and geographic distributions are related. Finally, we compared the association between chemotypes and virulence in diseased wheat crowns with crown rot or FHB.

\section{Materials and Methods}

Fusarium strains and DNA extraction. Wheat stem bases showing typical symptoms of crown rot were collected from 2009 to 2013 in approximately 70 counties in five provinces (Hebei, Shandong, Henan, Anhui, and Jiangsu). About two-thirds of the winter wheat in China is grown in these provinces. Anhui and Jiangsu are in the south and mostly in a wheat-rice rotation. Hebei, Shangdong, and Henan are in the north where a wheat-maize rotation system is 
prevalent. Epidemics of FHB occur frequently in Jiangsu, Anhui, and southern Henan because rainfall occurs frequently during wheat anthesis. FHB epidemics have been less in Hebei, Shangdong, and northern Henan, but are increasing.

The stem base specimens were rinsed with sterile distilled water and then surface-disinfected in $1 \%$ sodium hypochlorite for $3 \mathrm{~min}$. Each stem base was then thoroughly rinsed with sterile distilled water and placed on potato dextrose agar (PDA) plates containing $50 \mathrm{mg} /$ liter streptomycin. Plates were incubated 4 to 5 days at $25^{\circ} \mathrm{C}$. Fusarium colonies were subcultured on new PDA plates and purified using the single spore method. These single-spore samples were stored in PDA slants at $4^{\circ} \mathrm{C}$.

All the isolates were grown on PDA plates at $25^{\circ} \mathrm{C}$ for 5 to 6 days. Mycelia were harvested, frozen in liquid nitrogen, and ground to a fine powder using a mortar and pestle. Total genomic DNA was extracted using the E.Z.N.A. Fungal DNA Mini Kit (Omega BioTek, Germany).

Fusarium isolate identification. To determine whether the isolates belonged to the FGSC, PCR amplification was performed using the primer pair UBC85F410/UBC85R410, which was designed uniquely to amplify polymorphic DNA fragments (Table 1) (27). Amplification conditions were: $94^{\circ} \mathrm{C}$ for $2 \mathrm{~min}$; and 35 cycles of $94^{\circ} \mathrm{C}$ for $1 \mathrm{~min}, 62^{\circ} \mathrm{C}$ for $1 \mathrm{~min}, 72^{\circ} \mathrm{C}$ for $1 \mathrm{~min}$, and $72^{\circ} \mathrm{C}$ for $10 \mathrm{~min}$. The PCR amplicon of $332 \mathrm{bp}$ was visualized by electrophoresis on $1 \%$ agarose gel stained with ethidium bromide $\left(0.5 \mu \mathrm{g} \mathrm{ml}^{-1}\right)$. A 100-bp ladder (TaKaRa Biotechnology, Dalian, China) was used as a size standard.

If the above method failed, the gene sequence of an internal transcribed spacer (ITS) (40) and a phosphate permease (PHO) gene sequence was used for phylogenetic analysis (20).

Assay for $\boldsymbol{F}$. asiaticum and $\boldsymbol{F}$. graminearum. The primer set H3dStyI/H3R1 (Table 1) was used to amplify a part (approximately $223 \mathrm{bp}$ ) of the histone H3 gene sequence (21,31). The PCR amplicon from $F$. asiaticum strains was cleaved into 195- and 28-bp fragments with StyI, whereas the amplicon from $F$. graminearum strains was cleaved into 191- and 32-bp fragments with EcoRV. The total volume of the reaction mixture was $20 \mu$ l containing $10 \times$ PCR buffer, $25 \mathrm{mM}$ $\mathrm{MgCl}_{2}, 2.5 \mathrm{mM} \mathrm{dNTP}, 0.5 \mu \mathrm{M}$ of each primer, 5 units of rTaq polymerase $(\mathrm{TaKaRa})$, and $5 \mathrm{ng} / \mu \mathrm{l}$ of genomic DNA. Cycling parameters were: $94^{\circ} \mathrm{C}$ for $2 \mathrm{~min} ; 30$ cycles of $94^{\circ} \mathrm{C}$ for $1 \mathrm{~min}, 56^{\circ} \mathrm{C}$ for $1 \mathrm{~min}$, $72^{\circ} \mathrm{C}$ for $1 \mathrm{~min}$; and $72^{\circ} \mathrm{C}$ for $10 \mathrm{~min}$. The PCR amplicon of $223 \mathrm{bp}$ was confirmed as described above. A 100-bp ladder (TaKaRa) was used as a size standard. The remaining $8 \mu \mathrm{l}$ of the PCR mixture was used for digestion, with $10 \mathrm{U} / \mu \mathrm{l}$ StyI (Fermentas) or EcoRV (Fermentas) in a $20-\mu l$ reaction mixture, then incubated at $37^{\circ} \mathrm{C}$ for $4 \mathrm{~h}$, and resolved via electrophoresis in an $8 \%$ polyacrylamide gel.

Identification of chemotypes 3-AcDON, 15-AcDON, and NIV. The chemotype of individual FGSC isolates was determined using the specific primer described by Wang et al. (35). Primer set Tri13P1/Tri13P2 (Table 1) derived from the intergenic sequences of Tri13was synthesized and used for identification of the 3-AcDON, 15-AcDON, and NIV chemotypes, generating a 644-bp sequence for the 3 -AcDON chemotype, a 583-bp for the 15-AcDON chemotype, and an 859-bp for the NIV (12). Amplification conditions were $94^{\circ} \mathrm{C}$ for $4 \mathrm{~min}$ and then 35 cycles of $94^{\circ} \mathrm{C}$ for $1 \mathrm{~min}, 58^{\circ} \mathrm{C}$ for $40 \mathrm{~s}, 72^{\circ} \mathrm{C}$ for $40 \mathrm{~s}$, and $72^{\circ} \mathrm{C}$ for $6 \mathrm{~min}$. The PCR amplicon was confirmed as described above.

Virulence assays. To assay the virulence of Fusarium isolates for crown rot disease, the method described by Yang et al. was modified (38). Eighty representative isolates (50 of 15-AcDON, 17 of 3-AcDON, and 13 of NIV) collected from all five provinces from 2009 to 2013 were incubated on PDA plates at $25^{\circ} \mathrm{C}$ for 5 to 6 days before the mycelia were harvested.

A bioassay was conducted using winter wheat cultivar Yangmai158, which has moderate resistance to FHB. Wheat seeds were germinated in petri dishes on a stack of filter papers saturated with water. After 3 days, when wheat coleoptiles were 1 to $2 \mathrm{~cm}$ long, a mycelial plug, $5 \mathrm{~mm}$ in diameter, was removed from the margin of an actively growing culture of each isolate with a pipette tip. Plugs of each isolate were put around the wheat coleoptiles. Inoculated wheat seedlings were placed on water-saturated $21 \times 23 \mathrm{~cm}$ spunlace nonwoven fabric $(\Phi 2 \mathrm{~mm}$, Shaoxing Hengsheng New Material Technology Development Co., Ltd, China), which were then rolled up. Three replicates, each containing 10 seedlings, were used for each isolate. The seedlings were incubated in $25 / 15^{\circ} \mathrm{C}$ day/night temperatures and $80 \%$ relative humidity. The spunlace fabric rolls were dipped into a water bath for $30 \mathrm{~s}$ when the seedlings started to wilt. Control seedlings were inoculated with blank PDA.

The severity of crown rot was assessed 20 days after inoculation according to a 0 to 7 scale modified from $\mathrm{Li}$ et al. (14): 0 , no obvious signs; 1 , obvious partially necrotic lesion on coleoptile; 3 , coleoptile completely necrotic; 5 , first leaf sheath is obviously necrotic; 7 , entire plant is severely to completely necrotic. A disease index (DI) was then calculated for each replicate using the formula: $D I=\left(\sum \mathrm{n}_{\mathrm{s}} \mathrm{S} /\right.$ $7 \mathrm{~N}) \times 100$, where $S$ is the scale value of each plant, $n_{s}$ is the number of plants in the category, and $\mathrm{N}$ is the total number of plants assessed for replicate.

Winter wheat cultivar Yangmai158 was used to assay the virulence of crown rot isolates on wheat heads. Besides Fusarium isolates (17 of $15-\mathrm{AcDON}, 79$ of 3 -AcDON, and 24 of NIV) collected from infected crowns, 130 FHB isolates ( 80 of $15-A c D O N$, 39 of $3-A c D O N$, and 11 of NIV) collected in 2013 from the five provinces were also tested to compare the virulence of these two populations on wheat heads. These isolates were collected from the same five provinces as from 2009 to 2012. In late October, wheat seeds were sown in an outdoor nursery, spaced $35 \mathrm{~cm}$ to avoid crosscontamination. Conidiospores were prepared using $6 \%$ mung bean soup (37). Spore concentration was adjusted to obtain 1 to $2 \times 10^{5}$ spores $/ \mathrm{ml}$, confirmed with a hemocytometer, for inoculation at anthesis. Ten microliters of the spore suspension was injected into a central floret of a spike using a pipette. For each isolate, 10 heads were inoculated for analysis. The number of spikelets with signs of disease was counted at $7,14,21$, and 28 days postinoculation. Virulence was estimated by the mean number of diseased spikelets.

Mycotoxin measurements. Wheat spikelets were excised 30 days after inoculation and dried to approximately $15 \%$ water content before grinding with a whirlwind grinder (FSII, Zhejiang Top Instrument Co., Ltd, China). The finely ground wheat $(2.5 \mathrm{~g})$ was added to a $50-\mathrm{ml}$ centrifuge tube with $10 \mathrm{ml}$ of acetonitrile/water (84/16 $\mathrm{v} / \mathrm{v})$ and shaken on a rotary shaker for $4 \mathrm{~h}$. The fluid was then passed

Table 1. Primer sequences used in this study

\begin{tabular}{llc}
\hline Primer & \multicolumn{1}{c}{ Nucleotide sequence (5' to 3') } & Reference \\
\hline UBC85F410 & GCAGGGTTTGAATCCGAGAC & Schilling et al. (27) \\
UBC85R410 & AGAATGGAGCTACCAACGGC & Schilling et al. (27) \\
H3dStyI & AGCATCACCYGAACATCGCATCATCCCATG & Suga et al. (31) \\
H3R1 & TTGGACTGGATRGTAACACGC & Sugal et al. (31) \\
Tri13P1 & CTCSACCGCATCGAAGASTCTC & Wang et al. (36) \\
Tri13P2 & GAASGTCGCARGACCTTGTTTC & Wang et al. (36) \\
ITS1 & TCCGTAGGTGAACCTGCGG & Zhao et al. (40) \\
ITS4 & TCCTCCGCTTATTGATATGC & Zhao et al. (40) \\
PHO1 & ATCTTCTGGCGTGTTATCATG & O'Donnell et al. (20) \\
PHO6 & GATGTGGTTGTAAGCAAAGCCC & O'Donnell et al. (20) \\
\hline
\end{tabular}


through Bond Elut Mycotoxin (Agilent) and $2 \mathrm{ml}$ was removed and evaporated to dryness with nitrogen (33).

Extracts were analyzed by high-performance liquid chromatography (HPLC) on an HP1100 system with a C18 reversed phase column (Agilent ZORBAX Bonus-RP) and an ultraviolet detector at $220 \mathrm{~nm}$. The presence and amount of DON in the extracts was determined by comparing HPLC retention times and peaks with a DON standard (Sigma).

Statistical analysis. All data were analyzed using SAS software Version 9 (SAS Institute, Cary, NC). Because the data on virulence of wheat crown is ordinal and not normally distributed, it was analyzed using the nonparametric method described by Shah and Madden (28). PROC RANK was used to obtain midranks followed by PROC MIXED to calculate test statistics and significance levels. Data on virulence on wheat heads and DON content was analyzed using PROCGLM (general linear models).

\section{Results}

Isolate identification and trichothecene chemotypes. A 332-bp amplicon was observed following amplification with the primer pair UBC85F410/UBC85R410 in 160 isolates, indicating they belonged the FGSC (Table 2). For another 15 isolates missing the 332-bp amplicon, we sequenced the rDNA ITS and $P H O$ genes. Using NCBI BLAST, these isolates were identified as $F$. acuminatum, $F$. pseudograminearum, and $F$. avenaceum.

PCR assays with primer pair Tri13P1/P2 revealed that 95 of the 160 FGSC isolates produced a 644-bp fragment, indicating that all expressed 3-AcDON; 37 isolates produced a 583-bp fragment indicating the expression of $15-\mathrm{AcDON}$. For the remaining 28 isolates, an 859-bp PCR product was obtained and thus were classified as NIV.

Among the 160 FGSC isolates, PCR amplicons from 37 isolates using primer set $\mathrm{H} 3 \mathrm{dStyI} / \mathrm{H} 3 \mathrm{R} 1$ were cleaved by restriction enzyme EcoRV, and identified as $F$. graminearum (Table 2). One hundred and twenty-three isolates were identified as $F$. asiaticum, because the amplicons were cleaved by restriction enzyme StyI. Among $123 \mathrm{~F}$. asiaticum isolates, 95 isolates were 3-AcDON chemotype and 28 isolates were NIV chemotype (Table 2). Of the 37 isolates determined to be $F$. graminearum, all were 15 -AcDON.

Geographic distributions of species and trichothecene chemotypes. Isolates from all five provinces were analyzed for trichothecene chemotype distribution. Figure 1 illustrates the frequency distribution of the different chemotypes in the five provinces where the Fusarium isolates were collected. The predominant chemotype was 3-AcDON with respective percentages in Jiangsu, Henan, Anhui, and Hebei province of 59.2, 54.2, 67.8, and 62.5\%. It was followed by $15-A c D O N$ in Jiangsu and Henan and by NIV in Anhui and Hebei. No NIV isolates were found in Shandong, where $15-\mathrm{AcDON}$ was the predominant chemotype. Based on the data from these five provinces, the frequency of the 3 -AcDON chemotype was the highest and the number of the NIV and 15-AcDON chemotype isolates was almost equal.

Similarly, we determined that the $F$. asiaticum and $F$. graminearum species differed in distribution throughout the five provinces. $F$. asiaticum, with both $3-\mathrm{AcDON}$ and NIV chemotypes, was the predominant pathogen causing crown rot in these provinces except Shangdong, and $F$. graminearum with only the $15-\mathrm{AcDON}$ was the second most prevalent in all areas.

Virulence of FGSC isolates to wheat crown and heads. In this study, we modified the bioassay method of Yang et al. (38) to evaluate crown rot disease in wheat. Spunlace nonwoven fabric were used to roll the seedlings instead of paper towels, because spunlace nonwoven fabric stays intact longer than paper towels. To reduce time of infection, mycelial plugs were used as the inoculum to replace the spore suspension. This assay was based on disease symptoms typically associated with crown rot disease, namely dark necrotic lesions on the crown and stem base. The results showed that the pathogenicity of isolates of the 3-AcDON, 15-AcDON, and NIV chemotypes was not significantly different $(P=0.5434)$, although numerically, the mean disease index for 3 -AcDON isolates was higher (Fig. 2)

In the field assay, all crown rot isolates were able to cause head blight. By comparing the mean number of symptomatic spikelets, we found that the 3-AcDON isolates were the most aggressive, followed by $15-\mathrm{AcDON}$ and NIV. When comparing the virulence of FHB and crown rot isolates of the same chemotype, we found that the virulence of the crown rot and FHB isolates to wheat heads was not significantly different (Fig. 3).

DON production in wheat grains after Fusarium inoculation. Crown rot isolates and FHB isolates produced DON during the infection of wheat heads. The DON content in the grains after inoculation with crown rot isolates was 11.98 to $20.14 \mu \mathrm{g} / \mathrm{g}$ and that of the FHB isolates was 8.29 to $13.00 \mu \mathrm{g} / \mathrm{g}$. DON production by the $3-\mathrm{AcDON}$ and NIV crown rot isolates of chemotypes were significantly greater than that of the FHB isolates of the same chemotypes. There was no significant difference in DON production between the two 15-AcDON isolate populations (Fig. 4).

Table 2. Trichothecene chemotypes and phylogenetic species of Fusarium isolates collected from the five provinces

\begin{tabular}{|c|c|c|c|c|c|c|}
\hline \multirow[b]{2}{*}{ Province } & \multirow[b]{2}{*}{ Number of isolates } & \multicolumn{2}{|c|}{ Phylogenetic species and number of isolates } & \multicolumn{3}{|c|}{ Mycotoxin chemotypes, numbers of isolates } \\
\hline & & Name & Number & 3-AcDON & 15-AcDON & NIV \\
\hline \multirow[t]{5}{*}{$\overline{\text { Jiangsu }}$} & 83 & F. graminearum & 19 & - & 19 & - \\
\hline & & F. asiaticum & 57 & 45 & - & 12 \\
\hline & & F. acuminatum & 5 & - & - & - \\
\hline & & F. pseudoraminearum & 1 & - & - & - \\
\hline & & F. avenaaeum & 1 & - & - & - \\
\hline \multirow[t]{3}{*}{ Anhui } & 29 & F. graminearum & 4 & - & 4 & - \\
\hline & & F. asiaticum & 24 & 19 & - & 5 \\
\hline & & F. acuminatum & 1 & - & - & - \\
\hline \multirow[t]{3}{*}{ Henan } & 25 & F. graminearum & 7 & - & 7 & - \\
\hline & & F. asiaticum & 17 & 13 & - & 4 \\
\hline & & F. acuminatum & 1 & - & - & - \\
\hline \multirow[t]{3}{*}{ Hebei } & 26 & F. graminearum & 2 & - & 2 & - \\
\hline & & F. asiaticum & 22 & 15 & - & 7 \\
\hline & & F. acuminatum & 2 & - & - & - \\
\hline \multirow[t]{3}{*}{ Shandong } & 12 & F. graminearum & 5 & - & 5 & - \\
\hline & & F. asiaticum & 3 & 3 & - & - \\
\hline & & F. acuminatum & 4 & - & - & - \\
\hline \multirow[t]{2}{*}{ Total } & 175 & F. graminearum & 37 & - & 37 & - \\
\hline & & F. asiaticum & 123 & 95 & - & 28 \\
\hline
\end{tabular}




\section{Discussion}

We surveyed and developed an overall profile of the Fusarium pathogens causing crown rot in the major winter wheat growing provinces of Jiangsu, Anhui, Henan, Hebei, and Shandong of China. All three trichothecene chemotypes (3-AcDON, 15-AcDON, and NIV) associated with the FGSC were found. The principal causative species of crown rot were $F$. asiaticum and $F$. graminearum, but the chemotype composition of these two were significantly different; in $F$. asiaticum isolates, 3-AcDON and NIV chemotypes were present, whereas all $F$. graminearum isolates were $15-\mathrm{AcDON}$.
Fusarium species that produce DON predominate in North America, South America, and Europe, whereas those that produce both DON and NIV are found in Japan, Korea, and Nepal (8). The Australian pathogen population also consists of both NIV and DON producers $(2,32)$. Based on the results of this study, the trichothecene chemotypes of pathogens causing wheat crown rot were the same as those of pathogens that lead to FHB in the five provinces surveyed $(29,39)$, but their distributions differed. In previous work, $F$. asiaticum was the predominant phylogenetic species causing FHB in Jiangsu and Anhui provinces and $F$. graminearum was dominant in Henan,

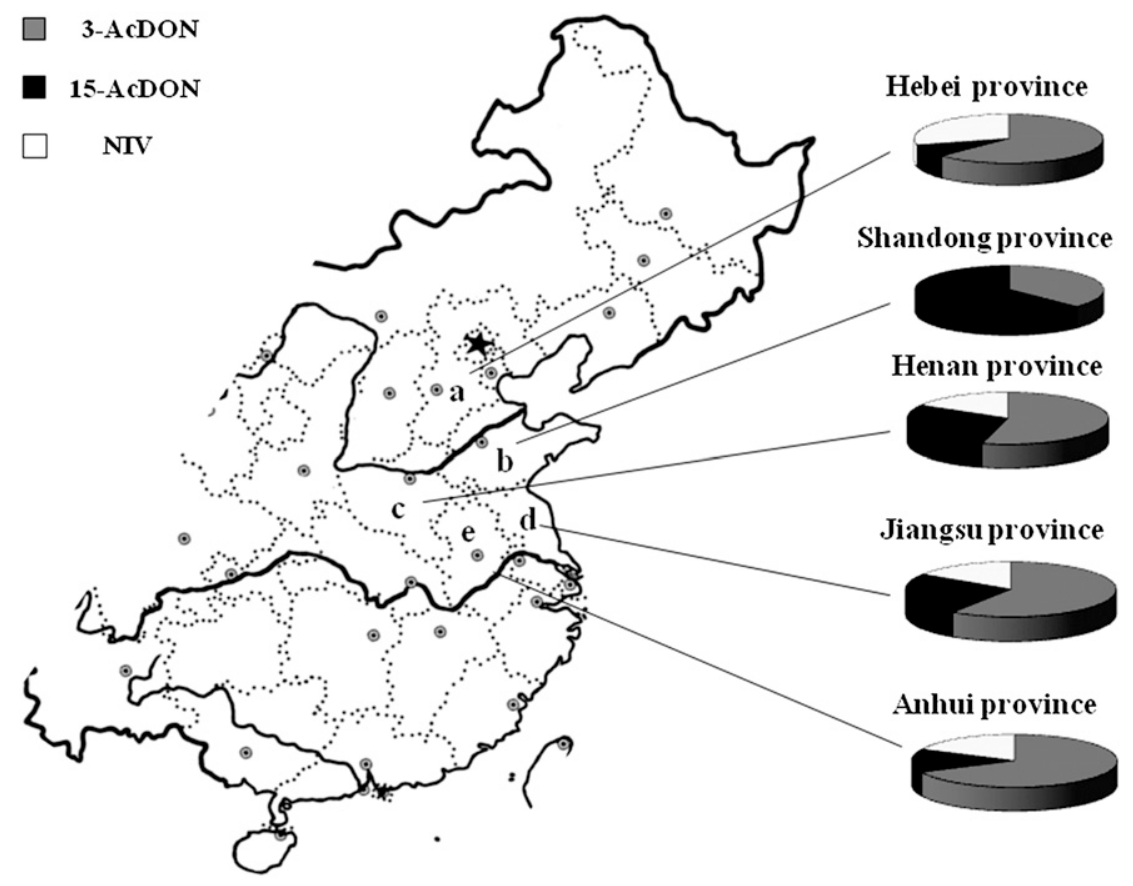

Fig. 1. Trichothecene chemotype frequencies in the five provinces of China, based on analyses of 160 FGSC isolates. (a) Hebei Province, with the frequency of 3-AcDON, $15-A c D O N$, and NIV being $62.5,8.3$, and $29.2 \%$, respectively. (b) Shandong Province, with the frequency of 3-AcDON, $15-A c D O N$, and NIV being $37.5,62.5 \%$, and none. (c) Henan Province, with the frequency of 3-AcDON, 15-AcDON, and NIV being 54.2, 29.1, and 16.7\%. (d) Jiangsu Province, with the frequency of 3-AcDON, 15-AcDON, and NIV being 59.2, 25, and 15.8\%. (e) Anhui Province, with the frequency of 3-AcDON, 15-AcDON, and NIV being 67.8, 14.3, and 17.9\%.

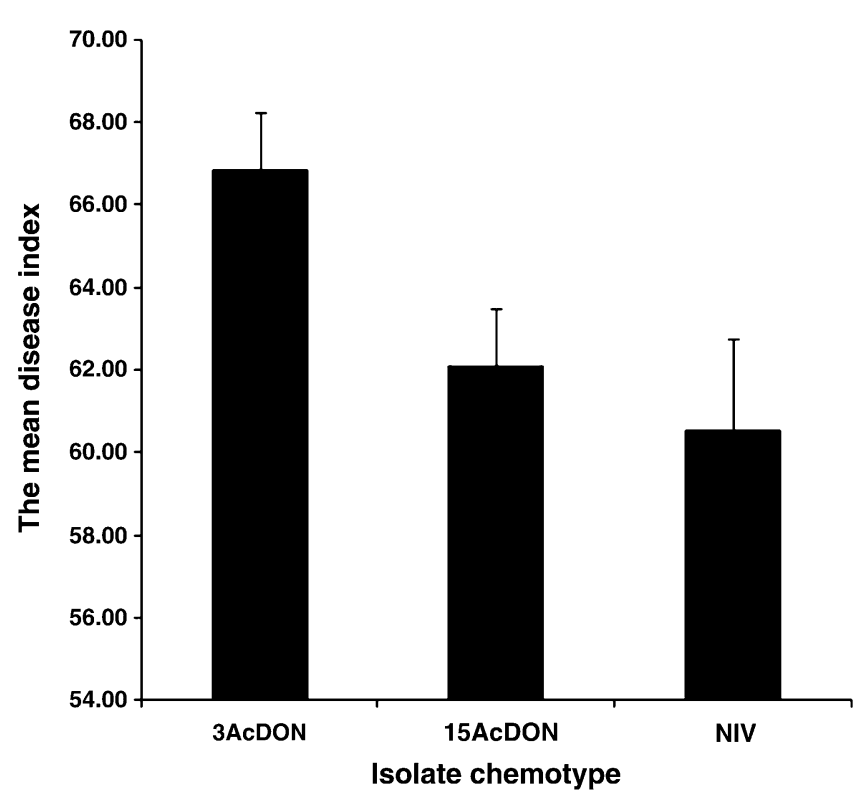

Fig. 2. Pathogenicity of crown rot isolates of the three chemotypes to wheat crown. There was no significant difference in pathogenicity among the three chemotypes determined by the nonparametric method described by Shah and Madden (28), $P=0.05$.

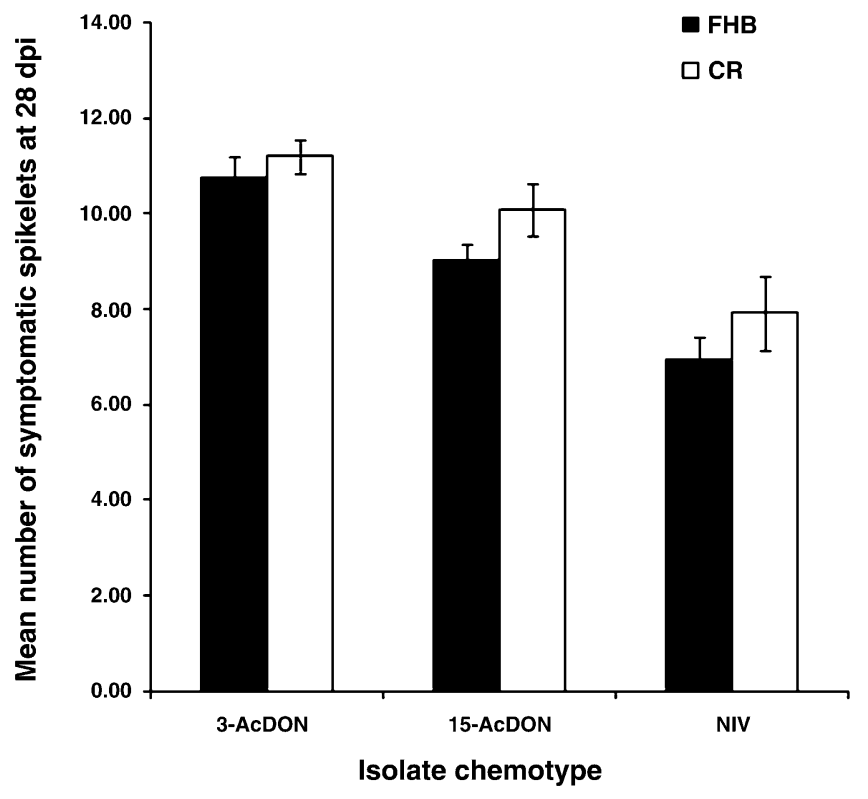

Fig. 3. Pathogenicity of Fusarium head blight and crown rot isolates of the three chemotypes to wheat heads. There was no significant difference in pathogenicity of Fusarium head blight and crown rot isolates among the three chemotypes. It was analyzed using PROCGLM (general linear models), $P=0.05$. 
Shangdong, and Hebei provinces. Similarly, 3-AcDON and NIV chemotypes were found mostly in Jiangsu and Anhui provinces, with 3-AcDON showing a decreasing trend from south to north. Frequency of the 15-AcDON chemotype was highest in Henan and Shangdong, and only the $15-A c D O N$ chemotype was found in Hebei (29). The present study showed that the $F$. asiaticum 3-AcDON chemotype was the predominant pathogen causing crown rot in all provinces except Shangdong. Distributions of the chemotypes causing FHB and crown rot were similar in the south (Jiangsu and Anhui), but chemotypes of the crown rot isolates were different from the FHB isolates in the northern provinces (Henan and Hebei).

Identification of the factors that cause differences in distribution of Fusarium and the mycotoxins they produce requires further research. Previous studies have compared the effectiveness of Gibberella zeae ascospores and conidia as inoculum for inciting FHB and crown rot (17). The cropping system and environmental conditions in different regions can determine whether FHB epidemics are initiated predominantly by ascospores or conidia (1). The primary inoculum of FHB was ascospores, and environmental conditions such as temperature that favor the production of ascospores may affect the distribution of the two Fusarium species.

Previous studies on FHB pathogens reported that the a majority of $F$. asiaticum isolates were collected from warmer regions of China, where the annual average temperature was above $15^{\circ} \mathrm{C}$. F. graminearum was distributed mainly in the cooler regions, where the annual average temperature was $15^{\circ} \mathrm{C}$ or lower $(25,39)$. However, there is no solid evidence to prove that higher temperatures favor ascospore production of $F$. asiaticum or that lower temperatures favor ascospore production of $F$. graminearum.

Another hypothesis is that the cropping system influences distribution of these pathogens. In the southern parts of China, rice is usually grown after wheat, while maize is planted after wheat in the north (25), and perhaps the two Fusarium species favor different crops. However, the primary inoculum of crown rot is mycelia in crop residue, and therefore disease prevalence may not be affected by the above factors. In other parts of the world, climate can strongly influence the diversity of Fusarium spp. that cause crown rot. For instance, the distributions of $F$. culmorum and $F$. pseudograminearum in the northwestern United States are influenced by climate (24).

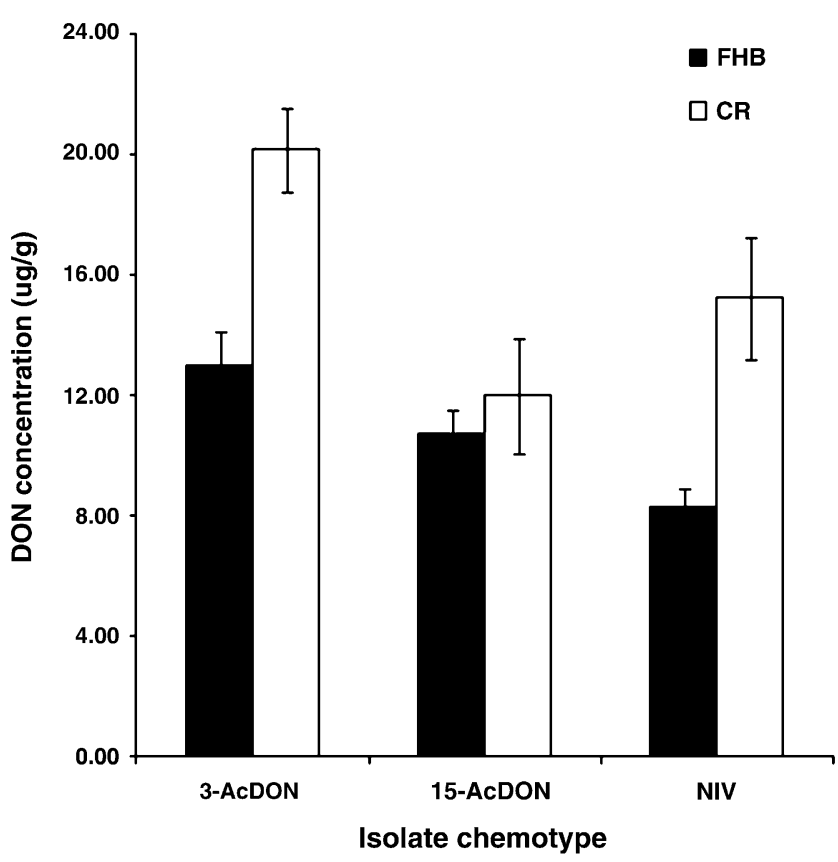

Fig. 4. Analysis of DON concentrations in wheat heads of Fusarium head blight and crown rot isolates of three chemotypes. The differences in DON concentration were significant between the Fusarium head blight and crown rot isolates of the 3-AcDON chemotype, and between those of the NIV chemotype. It was analyzed using PROCGLM (general linear models), $P=0.05$.
Some studies have reported differences in virulence in wheat heads among chemotypes of $F$. graminearum and $F$. asiaticum. $\mathrm{Li}$ et al. (13) reported that 3-AcDON producers were more virulent than NIV producers in the Yangtze basin. Gale et al. (9) found that DON producers synthesized approximately four times more toxin than did those producing NIV, and spread significantly faster in the wheat head in southern Louisiana (United States). However, there has been no similar report regarding the virulence of crown rot isolates in China. In this study, we found no statistical differences among chemotypes for disease index, but that disease index of the 3-AcDON isolates was numerically higher than $15-\mathrm{AcDON}$ and NIV isolates. Similarly, there was no statistical significance in average disease index of $F$. asiaticum and $F$. graminearum isolates, but disease index of $F$. asiaticum isolates was numerically larger than $F$. graminearum. This is the first report regarding chemotypes and their virulence in China that was based on large quantities of crown rot isolates.

Our results are in accord with those of Zhang et al. (39), who demonstrated that a highly toxigenic and aggressive 3-AcDONproducing $F$. asiaticum population is spreading from east to west in China. They also found a trend that 3 -AcDON producers and the alleles that are prevalent in 3 -AcDON producers are increasing in the population. The phenotypic analysis of that study showed that $F$. asiaticum that produce $3-\mathrm{AcDON}$ had advantages over those that produce NIV, which were probably driven by natural selection.

Using HPLC, we measured DON concentration of wheat kernels infected with crown rot or FHB isolates. We didn't find statistical significance in DON production among chemotypes, although DON production of 3-AcDON isolates was numerically higher than 15-AcDON and NIV isolates. DON concentrations of the different chemotypes correlated with virulence to wheat crown and heads. This result supports our preliminary research using trichothecene-nonproducing mutants obtained by transformation-mediated disruption of the trichodiene synthase gene (Tri5). Tri5-deletion mutants produced less disease on wheat crowns than the trichothecene-producing progenitor strain from which they were derived (data not shown).

The results of the present study showed that $3-A c D O N$ was the predominant chemotype of the wheat crown rot pathogen in the main winter wheat growing regions of China. Our research provides the foundation for monitoring trends in pathogen distribution as the global climate changes.

\section{Acknowledgments}

This research was funded by the National Non-Profit Industry-Funded Research and Special Projects (201303016) and by funds earmarked for the China Agricultural Research System (CARS-3-1-17). We thank Dr. Xiao-yi $\mathrm{Wu}$ for helping us perform the statistical analyses. We thank all of the technicians and students who helped in conducting the field trials and disease evaluations.

\section{References}

1. Bai, G. H., and Shaner, G. 1994. Scab of wheat: prospects for control. Plant Dis. 78:760-766.

2. Blaney, B. J., and Dodman, R. L. 2002. Production of zearalenone, deoxynivalenol, nivalenol and acetylated derivatives by Australian isolates of Fusarium graminearum and $F$. pseudograminearum in relation to source and culturing conditions. Aust. J. Agric. Res. 53:1317-1326.

3. Braun, H. J., Mergoum, M., Morgounov, A., Nicol, J. 2004. Adaptation of winter wheat to central and west Asia. CIMMYT Research Results. 27-32.

4. Burgess, L. W., Wearing, A. H., and Toussoun, T. A. 1975. Surveys of Fusaria associated with crown rot of wheat in eastern Australia. Aust. J. Agric. Res. 26 791-799.

5. Burgess, L. W., Backhouse, D., Summerell, B. A., and Swan, L. J. 2001. Crown rot of wheat. In Fusarium: Paul E. Nelson Memorial Symposium. (Eds BA Summerell, JF Leslie, D Backhouse, WL Bryden, LW Burgess) pp. 271-294. The American Phytopathological Society: St Paul, MN

6. Chakraborty, S., Liu, C. J., Mitter, V., Scott, J. B., Akinsanmi, O. A., Ali, S., Macky, R. D., Nicol, J., Backhouse, D., and Simpfendorfer, S. 2006. Pathogen population structure and epidemiology are keys to wheat crown rot and Fusarium head blight management. Australas. Plant Pathol. 35:643-655.

7. Chen, H. D., Wang, Z. M., and Yuan, S. Z. 2001. Study of occurrence characteristics and yield loss of the disease caused by wheat brown foot rot in Jiangsu province. J. Yangzhou Univ. 4:43-46.

8. Desjardins, A. E. 2006. Fusarium Mycotoxins: Chemistry, Genetics, and Biology. American Phytopathological Society, St. Paul, MN. 
9. Gale, L. R., Harrison, S. A., Ward, T. J., O’Donnell, K., Milus, E. A., Gale, S. W., and Kistler, H. C. 2011. Nivalenol-type populations of Fusarium graminearum and $F$. asiaticum are prevalent on wheat in southern Louisiana. Phytopathology 101:124-134.

10. Kumar, J., Schafer, P., Hüchelhoven, R., Langen, G., Baltruschat, H., Stein, E., Nagarajan, S., and Kogel, K. H. 2002. Bipolaris sorokiniana, a cereal pathogen of global concern: cytological and molecular approaches towards better control. Mol. Plant Pathol. 3:185-195.

11. Lamprecht, S. C., Marasas, W. F. O., Hardy, M. B., and Calitz, F. J. 2006. Effect of crop rotation on crown rot and the incidence of Fusarium pseudograminearum in wheat in the Western Cape, South Africa. Australas. Plant Pathol. 35:419-426.

12. Li, H. P., Wu, A. B., Zhao, C. S., Scholten, O., Löffler, H., and Liao, Y. C. 2005. Development of a generic PCR detection of deoxynivalenol- and nivalenol-chemotypes of Fusarium graminearum. FEMS Microbiol. Lett. 243:505-511.

13. Li, W., Chen, Y., Zhang, X. X., Zhang, B. Q., Yu, H. S., and Chen, H. G. 2011. Pathogenic fungi of wheat brown foot rot and their pathogenicity in China. J. Triticeae Crops. 31:170-175.

14. Li, X. M., Liu, C. J., Chakraborty, S., Manners, J. M., and Kazan, K. 2008. A simple method for the assessment of crown rot disease severity in wheat seedlings inoculated with Fusarium pseudograminearum. Phytopathology 156:751-754.

15. Miller, J. D., Greenhalgh, R., Wang, Y. Z., and Lu, M. 1991. Trichothecene chemotypes of three Fusarium species. Mycologia 83:121-130.

16. Mishra, P. K., Tewari, J. P., Clear, R. M., and Turkington, T. K. 2006. Genetic diversity and recombination within populations of Fusarium pseudograminearum from western Canada. Int. Microbiol. 9:65-68.

17. Mitter, V., Francl, L. J., Ali, S., Simpfendorfer, S., and Chakraborty, S. 2006. Ascosporic and conidial inoculum of Gibberella zeae play different roles in Fusarium head blight and crown rot of wheat in Australia and the USA. Australas. Plant Pathol. 35:441-452.

18. Mudge, A. M., Macky, R. D., Dong, Y. H., Gardiner, D. M., White, R. G., and Manners, J. M. 2006. A role for the mycotoxin deoxynivalenol in stem colonisation during crown rot disease of wheat caused by Fusarium graminearum and Fusarium pseudograminearum. Physiol. Mol. Plant Pathol. 69:73-85

19. Nicol, J. M., Bagci, A., Hekimhan, H., Bolat, N., Braun, H. J., and Trethowan, R. 2004. Strategy for the identification and breeding of resistance to dryland root rot complex for international spring and winter wheat breeding programs. Proceedings of the 4th International Crop Science Congress, Brisbane, Australia.

20. O'Donnell, K., Kistler, H. C., Tacke, B. K., and Casper, H. H. 2000. Gene genealogies reveal global phylogeographic structure and reproductive isolation among lineages of Fusarium graminearum, the fungus causing wheat scab. Proc. Natl. Acad. Sci. USA 97:7905-7910.

21. O'Donnell, K., Ward, T. J., Geiser, D. M., Kistler, H. C., and Aoki, T. 2004. Genealogical concordance between the mating type locus and seven other nuclear genes supports formal recognition of nine phylogenetically distinct species within the Fusarium graminearum clade. Fungal Genet. Biol. 41: 600-623.

22. Pettitt, T. R., and Parry, D. W. 2001. Effect of temperature on Fusarium foot rot of wheat. Pages 145-160 in: Fusarium: Paul E. Nelson Memorial Symposium. B. A. Summerell, J. F. Leslie, D. Backhouse, W. L. Bryden, and L. W. Burgess, eds. The American Phytopathological Society, St Paul, MN.

23. Pettitt, T., Xu, X., and Parry, D. 2003. Association of Fusarium species in the wheat stem rot complex. Eur. J. Plant Pathol. 109:769-774.

24. Poole, G. J., Smiley, R. W., Walker, C., Huggins, D. R., Rupp, R., Abatzoglou, J., Garland Campbell, K. A., and Paulitz, T. C. 2013. Effect of climate on the distribution of Fusarium species causing crown rot of wheat in the Pacific Northwest of the US. Phytopathology 103:1130-1140.

25. Qu, B., Li, H. P., Zhang, J. B., Xu, Y. B., Huang, T., Wu, A. B., Zhao, C. S. Carter, J., Nicholson, P., and Liao, Y. C. 2008. Geographic distribution and genetic diversity of Fusarium graminearum and $F$. asiaticum on wheat spikes throughout China. Plant Pathol. 57:642-651.

26. Sarver, B. A. J., Ward, T. J., Gale, L. R., Broz, K., Kistler, H. C., Aoki, T., Nicholson, P., Carter, J., and O'Donnell, K. 2011. Novel Fusarium head blight pathogens from Nepal and Louisiana revealed by multilocus genealogical concordance. Fungal Genet. Biol. 48:1096-1107.

27. Schilling, A. G., Moller, E. M., and Geiger, H. H. 1996. Polymerase chain reaction-based assays for species-specific detection of Fusarium culmorum $F$. graminearum and $F$. avenaceum. Phytopathology 86:515-522.

28. Shah, D. A., and Madden, L. V. 2004. Nonparametric analysis of ordinal data in designed factorial experiments. Phytopathology 94:33-43.

29. Shen, C. M., Hu, Y. C., Li, W., and Chen, H. G. 2012. Geographic distribution of trichothecene chemotypes of the Fusarium graminearum species complex in major winter wheat production areas of China. Plant Dis. 96:1172-1198.

30. Smiley, R. W., Gourlie, J. A., Easley, S. A., Patterson, L. M., and Whittaker, R. G. 2005. Crop damage estimates for crown rot of wheat and barley in the Pacific Northwest. Plant Dis. 89:595-604.

31. Suga, H., Karugia, G. W., Ward, T., Gale, L. R., Tomimura, T., Nakajima, T. Miyasaka, A., Koizumi, S., Kageyama, K., and Hyakumachi, M. 2008. Molecular characterization of the Fusarium graminearum species complex in Japan. Phytopathology 98:159-166.

32. Tan, M. K., Simpfendorfer, S., Backhouse, D., and Murray, G. M. 2004 Occurrence of Fusarium head blight (FHB) in southern NSW in 2000 identification of causal fungi and determination of putative chemotype of Fusarium graminearum isolates by PCR. Australas. Plant Pathol. 33:385-392.

33. Veldman, A., Borggreve, G. J., Mulders, E. J., and Lagemaat, D. V. 1992. Occurrence of the mycotoxins ochratoxin A, zearalenone and deoxynivalenol in feed components. Food Addit. Contam. 9:647-655.

34. Von der Ohe, C., Gauthier, V., Tamburic-Ilincic, L., Brule-Babel, A., Fernando, W. G. D., Clear, R., Ward, T. J., and Miedaner, T. 2010. A comparison of aggressiveness and deoxynivalenol production between Canadian Fusarium graminearum isolates with 3-acetyl and 15acetyldeoxynivalenol chemotypes in field-grown spring wheat. Eur. J. Plant Pathol. 127:407-417.

35. Wang, J. H., Li, H. P., Qu, B., Zhang, J. B., Huang, T., Chen, F. F., and Liao, Y C. 2008. Development of a generic PCR detection of 3-acetyldeoxynivalenol15-acetyldeoxynivalenol- and nivalenol-chemotypes of Fusarium graminearum clade. Int. J. Mol. Sci. 9:2495-2504

36. Ward, T. J., Bielawski, J. P., Kistler, H. C., Sullivan, E., and O'Donnell, K. 2002. Ancestral polymorphism and adaptive evolution in the trichothecene mycotoxin gene cluster of phytopathogenicFusarium. Proc. Natl. Acad. Sci. USA 99:9278-9283.

37. Williams, K. J., Dennis, J. I., Smyl, C., and Wallwork, H. 2002. The application of species-specific assays based on the polymerase chain reaction to analyse Fusarium crown rot of durum wheat. Australas. Plant Pathol. 31:119-129.

38. Yang, X., Ma, J., Li, H., Ma, H., Yao, J., and Liu, C. 2010. Different genes can be responsible for crown rot resistance at different developmental stages of wheat and barley. Eur. J. Plant Pathol. 128:495-502.

39. Zhang, H., Van, L. T., Waalwijk, C., Chen, W., Xu, J., Xu, J., Zhang, Y., and Feng, J. 2012. Population analysis of the Fusarium graminearum species complex from wheat in China show a shift to more aggressive isolates. PLoS ONE 7:e31722.

40. Zhao, Z. H., and Lu, G. Z. 2008. Fusarium sinensis sp. nov., a new species from wheat in China. Mycologia 100:746-751. 